\title{
Response of Preterm Infants to 2 Noninvasive Ventilatory Support Systems: Nasal CPAP and Nasal Intermittent Positive-Pressure Ventilation
}

\author{
Carmen Salum Thomé Silveira MD, Kamila Maia Leonardi, Ana Paula Carvalho Freire Melo, \\ José Eduardo Zaia PhD, and Marisa Afonso Andrade Brunherotti PhD
}

\begin{abstract}
BACKGROUND: Noninvasive ventilation (NIV) in preterm infants is currently applied using intermittent positive pressure ( 2 positive-pressure levels) or in a conventional manner (one pressure level). However, there are no studies in the literature comparing the chances of failure of these NIV methods. The aim of this study was to evaluate the occurrence of failure of 2 noninvasive ventilatory support systems in preterm neonates over a period of $48 \mathrm{~h}$. METHODS: A randomized, prospective, clinical study was conducted on 80 newborns (gestational age $<37$ weeks, birthweight $<2,500$ g). The infants were randomized into 2 groups: 40 infants were treated with nasal CPAP and 40 infants with nasal intermittent positive-pressure ventilation (NIPPV). The occurrence of apnea, progression of respiratory distress, nose bleeding, and agitation was defined as ventilation failure. The need for intubation and re-intubation after failure was also observed. RESULTS: There were no significant differences in birth characteristics between groups. Ventilatory support failure was observed in 25 (62.5\%) newborns treated with nasal CPAP and in $12(30 \%)$ newborns treated with NIPPV, indicating an association between NIV failure and the absence of intermittent positive pressure (odds ratio $[\mathrm{OR}] 1.22, P<.05)$. Apnea $(32.5 \%)$ was the main reason for nasal CPAP failure. After failure, $25 \%$ (OR 0.33) of the newborns receiving nasal CPAP and 12.5\% (OR 0.14) receiving NIPPV required invasive mechanical ventilation. CONCLUSIONS: Ventilatory support failure was significantly more frequent when nasal CPAP was used. Key words: continuous positive airway pressure; intermittent positive-pressure ventilation; newborn; infant; positive-pressure breathing. [Respir Care 2015;60(12):1772-1776. () 2015 Daedalus Enterprises]
\end{abstract}

\section{Introduction}

Noninvasive ventilation (NIV) is a recognized and appreciated tool for the care of preterm infants. Two modalities are used: nasal CPAP with intermittent positive-pressure ventilation (NIPPV) and nasal CPAP. Studies were conducted to identify the positive and negative effects of these modalities in preterm infants. There is evidence in-

Ms Silveira is affiliated with Pediatrics and Ms Leonardi and Melo are affiliated with Physiotherapy, Hospital Santa Casa de Franca, Franca, São Paulo, Brazil. Mr Zaia and Ms Brunherotti are affiliated with the Program in Health Promotion, University of Franca, Franca, São Paulo, Brazil.

This is Brazilian Clinical Trials Registry RBR-7d9dth.

The authors have disclosed no conflicts of interest. dicating some advantages of NIPPV over nasal CPAP. ${ }^{1-6}$ It has been demonstrated that preterm infants with respiratory distress syndrome receiving NIPPV benefit from a reduction in the need for invasive ventilation during the first $72 \mathrm{~h}$ of life compared with those receiving nasal CPAP. ${ }^{7}$ However, no difference in the survival rate of extremely premature infants without bronchopulmonary dysplasia was observed between modalities. ${ }^{8}$

NIV using intermittent positive pressure is increasingly used in neonatal ICUs; however, no uniform indications or

Correspondence: Carmen Salum Thomé Silveira, Rua Pasteur, 1300, ap-111, CEP, 14400-650 Franca, São Paulo, Brazil. E-mail: cstsilveira@gmail.com.

DOI: $10.4187 /$ respcare. 03565 
parameters are used by the institutions applying this modality. ${ }^{6.9}$ Thus, the chances of NIV failure in preterm infants using these 2 modalities remain unknown, but it is believed that NIPPV provides advantages in neonatal outcomes. Therefore, the objective of this study was to evaluate the occurrence of failure of 2 noninvasive ventilatory support systems in preterm neonates over a period of $48 \mathrm{~h}$.

\section{Methods}

\section{Subjects}

This was a controlled, randomized, single-blind study with 2 parallel arms. The study was conducted in the neonatal ICU of a public tertiary care hospital and was approved by the ethics committee of the hospital (protocol 070/2009). The infants were included in the study after their parents and/or legal guardians had signed the informed consent form.

Criteria for inclusion in the study were a birthweight of $<2,500 \mathrm{~g}$, a gestational age of $<37$ weeks, and the use of noninvasive ventilatory support applied with nasal prongs. Infants of both sexes were included. NIV was chosen as the first option of ventilatory intervention and/or after orotracheal extubation. Newborns who had congenital malformations, abdominal surgeries, and infections and term newborns were excluded.

Infants who were treated with invasive mechanical ventilation before nasal CPAP and who received an exogenous surfactant were diagnosed with respiratory distress syndrome according to clinical (persistent cyanosis and a Silverman-Anderson score of $\geq 7$ ) and radiological (diffuse reticulogranular pattern in both lungs and positive air bronchogram) criteria. ${ }^{10}$ Nasal CPAP was selected as the initial therapy based on the clinical evolution of the infants and was applied when oxygen concentrations $>40 \%$ were necessary for the maintenance of $\mathrm{P}_{\mathrm{aO}_{2}}$ at $>50$ $\mathrm{mm} \mathrm{Hg}$.

At the time of indication of nasal CPAP, the infants were randomized into 2 groups by drawing lots using sealed envelopes with the following identification: nasal CPAP group (flow $8 \mathrm{~L} / \mathrm{min}$, PEEP $5 \mathrm{~cm} \mathrm{H}_{2} \mathrm{O}, \mathrm{F}_{\mathrm{IO}_{2}}$ 0.21-0.40) and NIPPV group (peak inspiratory pressure $15 \mathrm{~cm} \mathrm{H}_{2} \mathrm{O}$, PEEP $5 \mathrm{~cm} \mathrm{H}_{2} \mathrm{O}$, inspiratory time $0.6 \mathrm{~s}$, breathing frequency 14 breaths/min, flow $\left.8 \mathrm{~L} / \mathrm{min}, \mathrm{F}_{\mathrm{IO}_{2}} 0.21-0.40\right) .{ }^{11}$

In this study, clinical indicators such as heart rate and oxygen saturation were monitored with a Dixtal DX2010 monitor (Dixtal Biomedica, São Paulo, Brazil), and breathing frequency was measured by counting the number of breaths over a period of $1 \mathrm{~min}$. Six records of the clinical indicators were obtained in the first $48 \mathrm{~h}$ of NIV. The first recording was performed, on average, $5 \mathrm{~h}$ after the instal-

\section{QUICK LOOK}

\section{Current knowledge}

Noninvasive ventilation (NIV) and nasal CPAP are 2 common techniques of respiratory support in neonates. There is some evidence indicating advantages of NIV over nasal CPAP. Recent studies demonstrated that preterm infants with respiratory distress syndrome receiving NIV benefit from a reduction in the need for invasive ventilation during the first $72 \mathrm{~h}$ of life compared with those receiving nasal CPAP.

\section{What this paper contributes to our knowledge}

In this prospective randomized trial, no significant differences in heart rate, breathing frequency, or $\mathrm{O}_{2}$ saturation were identified between the 2 groups. The mean values of these variables were within the normal range for age during NIV. However, there was evidence that failure was greater in the nasal CPAP group, as demonstrated by the higher frequency of apnea episodes and the need for intubation.

lation of noninvasive ventilatory support, and the second was performed $12 \mathrm{~h}$ after the first recording.

NIV failure requiring modification of ventilatory support was defined as presentation by the infant of apnea (suspension of breathing for $>20 \mathrm{~s}$ accompanied by bradycardia and cyanosis), ${ }^{12}$ nose bleeding (blood in the nasal cavity causing nasal obstruction), agitation (continuous crying with persistent body movement and contracted facial expression representing pain), and increased respiratory distress (based on the Silverman-Anderson score). The need for intubation and re-intubation after NIV failure was also observed.

\section{Statistical Analysis}

The sample size was calculated considering a frequency of NIPPV and nasal CPAP failure of $30 \%$ and $60 \%$, respectively; a bilateral test with a $5 \%$ level of significance; and a test power of 80\%: 40 infants per group. The chisquare test was used for statistical analysis to verify the association between NIV failure and pressure level and between the first option of ventilation at birth and newborn birthweight. The total number of occurrences of failure per pressure level and not the individual occurrence was considered for the analysis of NIV failure. All statistical analyses were performed using InStat 3.06 (GraphPad Software, San Diego, California). Differences were considered to be significant when $P<.05$. 
Table 1. Biological Characteristics of the Preterm Infants Monitored in the Study Who Received Noninvasive Ventilation

\begin{tabular}{lcrr}
\hline \hline \multicolumn{1}{c}{ Variable } & Nasal CPAP & NIPPV & $P^{*}$ \\
\hline Birth weight, g & $1.4 \pm 401$ & $1.3 \pm 446$ & .64 \\
Gestational age, wk & $30.3 \pm 2.4$ & $30.4 \pm 2.4$ & .86 \\
Breathing frequency, breaths/min & $49.8 \pm 6.0$ & $47.8 \pm 9.8$ & .37 \\
Heart rate, beats/min & $141.7 \pm 12.5$ & $143.8 \pm 14.8$ & .58 \\
Oxygen saturation, \% & $95.8 \pm 1.7$ & $96.4 \pm 1.5$ & .19 \\
& & & \\
Values are presented as mean \pm SD. & & & \\
$*$ Chi-square test. & & & \\
NIPPV = nasal intermittent positive-pressure ventilation & & \\
& & & \\
\hline
\end{tabular}

Table 2. Characteristics of the Preterm Infants Monitored in the Study Who Received Noninvasive Ventilation

\begin{tabular}{lcccc}
\hline \hline \multicolumn{1}{c}{ Characteristic } & $\begin{array}{c}\text { Total Cohort } \\
(N=80)\end{array}$ & $\begin{array}{c}\text { Nasal CPAP } \\
(n=40)\end{array}$ & $\begin{array}{c}\text { NIPPV } \\
(n=40)\end{array}$ & $P$ \\
\hline Prenatal steroids & $21(26.2)$ & $10(25)$ & $11(27.5)$ & .31 \\
Surfactant use & $39(48.7)$ & $19(47.5)$ & $20(50.0)$ & .11 \\
Cesarean section & $56(70.0)$ & $27(67.5)$ & $29(72.5)$ & .63 \\
Male & $44(55.0)$ & $23(57.5)$ & $21(52.5)$ & .31
\end{tabular}

Values are presented as $n(\%)$

$\mathrm{NIPPV}=$ nasal intermittent positive-pressure ventilation

\section{Results}

\section{Maternal and Infant Characteristics}

Eighty preterm infants with birthweights of $540-2,450$ $\mathrm{g}(1.337 \pm 422 \mathrm{~g})$ and gestational ages of 24-36 weeks ( $30.3 \pm 2.4$ weeks) participated in this study. Of these, $55 \%$ were boys. None of the infants died during the study period. The clinical profile was homogeneous, with no significant difference between groups (Tables 1 and 2). All infants were treated with noninvasive ventilatory support, and they were divided into 2 groups: nasal CPAP $(n=40)$ or NIPPV $(n=40)$. The mean age of the infants at the time of introduction of noninvasive ventilatory support was $3.9 \pm 4.8 \mathrm{~d}$.

The influence of birthweight and the first option of ventilatory support at birth were compared between groups. There was no significant difference in weight between nasal CPAP (up to $1,500 \mathrm{~g}[72-5 \%]$ vs $1,501-2,450 \mathrm{~g}$ [27-5\%], $P=.97$ ) and CPAP (up to $1,500 \mathrm{~g}[75-0 \%]$ vs $1,501-2,450 \mathrm{~g}[25-0 \%], P>.99)$ or the first option $(P=$ .44) between groups.

The age of the mothers of the infants participating in the study was $26.3 \pm 5.8$ versus $26.2 \pm 5.6 \mathrm{y}$ in the nasal CPAP and NIPPV groups, respectively. The cesarean section rate was $57.5 \%$ versus $72.5 \%$. The percentage of multiparous women was $67.5 \%$ versus $57.5 \%$.

\section{Indicators Analyzed}

No significant differences in mean breathing frequency, heart rate, or oxygen saturation were observed between the groups of newborns, with the values being within the normal range for age (see Table 1). The newborns monitored in this study were homogeneous in terms of biological characteristics, with no significant differences between groups. Half of the infants in each group received exogenous surfactant, prenatal steroids were used by only $26.1 \%$ of the mothers, and $70 \%$ of the infants were born by cesarean section (see Table 2).

A significant association was observed between ventilation failure and the absence of intermittent positive pressure (odds ratio 1.22, $P=.02$ ). During $48 \mathrm{~h}$ of NIV, the failure frequency was higher in infants treated with nasal CPAP $(62.5 \%)$ compared with infants treated with NIPPV (only $30 \%$ ) (Table 3 ).

In the group treated with nasal CPAP, apnea was the main reason for NIV failure $(32.5 \%)$, followed by respiratory distress and nose bleeding $(12.5 \%)$ and agitation at a lower frequency (5\%). However, the reasons for NIV failure were less frequent in the NIPPV group (apnea $12.5 \%$, respiratory distress $7.5 \%$, agitation $10 \%$ ) (see Table 3). After NIV failure due to the reasons cited, the introduction of invasive mechanical ventilation was necessary in $25 \%$ of the infants treated with nasal CPAP (odds ratio 0.33) and in $12.5 \%$ of those treated with NIPPV (odds ratio $0.14)$.

\section{Discussion}

NIV by NIPPV has been a frequent option in ICUs. Some advantages of this modality have been demonstrated, but randomized prospective studies are currently needed to show the performance of this modality in groups of preterm infants.

In this randomized study, preterm infants were selected to receive nasal CPAP and NIPPV. The groups were homogeneous in terms of biological characteristics, with the absence of significant differences, a fact that permitted comparison between groups. None of the infants died during the study period.

Eighty newborns were monitored in this study, which permitted us to determine the number of occurrences of failure of the 2 NIV modalities over a period of $48 \mathrm{~h}$. There are no studies in the literature describing the association between complications of nasal CPAP and the duration of ventilatory support. However, some evidence indicates that a longer duration of nasal CPAP increases nasal septum injuries. ${ }^{13,14}$

The modality of NIPPV has some advantages over nasal CPAP, the main being a reduction in apnea episodes. ${ }^{6-16}$ Other advantages include a reduction in respiratory work 
Table 3. Noninvasive Ventilation Failure Over a Period of $48 \mathrm{~h}$ in the Preterm Infants Monitored in the Study

\begin{tabular}{lcccc}
\hline \hline \multicolumn{1}{c}{ Reason for Failure } & Nasal CPAP $(n=40), n(\%)$ & Odds Ratio (95\% CI) & NIPPV $(n=40), n(\%)$ & Odds Ratio (95\% CI) \\
\hline Apnea & $13(32.5)$ & $0.48(0.25-0.92)$ & $5(12.5)$ & $0.14(0.06-0.35)$ \\
Respiratory distress & $5(12.5)$ & $0.14(0.06-0.35)$ & $3(7.5)$ & $0.08(0.03-0.25)$ \\
Nose bleeding & $5(12.5)$ & $0.14(0.06-0.35)$ & $0(0)$ & $4(10.0)$ \\
Agitation & $2(5.0)$ & $0.05(0.01-0.20)$ & $0.11(0.04-030)$ \\
Frequency of failure (total) & $25(62.5)$ & $1.22(0.66-2.26) *$ & $12(30.0)$ & $0.43(0.22-0.83)$ \\
$P$ & $.02^{*}$ & & & \\
Intubation/mechanical ventilation & $3(7.5)$ & $0.08(0.03-0.25)$ & $3(7.5)$ & $0.08(0.03-0.25)$ \\
Re-intubation/mechanical ventilation & $7(17.5)$ & $0.21(0.10-0.47)$ & $2(5.0)$ & $0.05(0.01-0.20)$ \\
Total No. of infants with mechanical ventilation & $10(25.0)$ & $0.33(0.17-0.67)$ & $5(12.5)$ & $0.14(0.06-0.35)$ \\
$P$ & .15 & &
\end{tabular}

$* P<.05$, significant association between noninvasive ventilation failure and pressure level (chi-square test).

$\mathrm{NIPPV}=$ nasal intermittent positive-pressure ventilation

and in the need for invasive ventilation for the preterm infant. ${ }^{1-6,17,18}$ In the present study, a significant association was observed between NIV failure and the absence of intermittent positive pressure $(P=.02$, odds ratio 1.22$)$. Only $30 \%(n=12)$ of the infants treated with NIPPV failed this modality. In 5 (42\%) newborns, the reason for failure was apnea, and 2 (40\%) of these infants required invasive mechanical ventilation. In contrast, failure occurred in $62.5 \%(n=25)$ of the infants treated with nasal CPAP. Most failure episodes were due to apnea $(n=13$, $52 \%)$; of these, $10(77 \%)$ infants required orotracheal intubation. Thus, apnea was the most frequent reason for NIV failure, particularly nasal CPAP failure; $69.2 \%$ of these infants weighed $<1,200 \mathrm{~g}$, and the gestational age was $<32$ weeks. The data obtained support the results of other studies. ${ }^{6,15,16}$

Nose bleeding and agitation were less common reasons for failure of the 2 modalities. The period of $48 \mathrm{~h}$ of NIV used in this study may have contributed to the small number of episodes of nose bleeding because this event is usually observed during prolonged periods of ventilatory support. ${ }^{12}$ Another factor was the use of a hydrocolloid plate in the nostrils, which permits better fixation and decreases displacement of the device.

In the nasal CPAP group, 6 (24\%) infants failed the modality within $24 \mathrm{~h}$ and $19(76 \%)$ infants within $48 \mathrm{~h}$ of ventilatory support. In the NIPPV group, 7 (58.3\%) infants failed nasal support within $24 \mathrm{~h}$ and $5(41.7 \%)$ infants within $48 \mathrm{~h}$. Thus, NIV failure tended to be greater in the nasal CPAP group after $24 \mathrm{~h}$ of ventilatory support.

Infants in the nasal CPAP group who did not require mechanical ventilation after NIV failure and who presented with apnea $(n=3)$ and respiratory distress $(n=5)$ received NIPPV, and those with agitation $(n=2)$ and bleeding $(n=5)$ were removed from noninvasive support and placed under an oxygen hood. In the NIPPV group, infants presenting with agitation $(n=4)$ were removed from noninvasive support after failure and placed under an oxygen hood, whereas newborns with apnea $(n=3)$ continued to be treated with this modality for a period of $>48 \mathrm{~h}$. No difference between groups was observed for newborns who received mechanical ventilation before NIV as a first option and who failed NIV.

Three of the infants monitored in this study had a prescription for bronchopulmonary dysplasia medication. Two of them were part of the NIV failure group: one in the nasal CPAP group due to apnea who required NIPPV and one in the NIPPV group due to respiratory distress who required re-intubation.

The chance for NIV failure was higher for the nasal CPAP modality. The occurrences observed were apnea, respiratory distress, nose bleeding, and re-intubation. Agitation was the least frequent occurrence in this modality. However, the number of occurrences was low in the 2 NIV modalities.

Comparison of the 2 NIV modalities revealed no significant differences in heart rate, breathing frequency, or oxygen saturation between the 2 groups. The mean values of these variables were within the normal range for age during NIV. These findings agree with other studies that also found no significant clinical differences between the 2 modalities. ${ }^{2,9,14,19}$

Prematurity itself leaves the newborn vulnerable. In this study, the use of NIPPV at the beginning of NIV support was associated with a lower chance of failure. The findings therefore support the use of this modality in clinical practice to attenuate the negative effects in preterm infants.

We believe that the intermittent positive inspiratory pressure generated with NIPPV increases the number of afferent sensory stimuli, and the respiratory system responds with better drive, thus reducing the episodes of apnea. However, it is worth noting that the objective of this study was to observe the indicators over a period of $48 \mathrm{~h}$ of NIV, 
with the indicators being recorded once/d. Evaluation of outcomes over longer periods of observation is therefore necessary. In this sample, a test was applied for comparison, which revealed no statistically significant difference in gestational age or first-option ventilatory support between groups, in an attempt to reduce confounding factors. In this respect, groups including a larger number of subjects and subdivided according to gestational age may be more representative.

\section{Conclusions}

This study showed that the 2 NIV modalities were similar in terms of clinical indicators, demonstrating no advantages of one modality over the other. However, there was evidence that NIV failure was significantly associated with the nasal CPAP group, as demonstrated by the higher frequency of apnea episodes and the need for re-intubation.

\section{REFERENCES}

1. Lemyre B, Davis PG, De Paoli AG, Kirpalani H. Nasal intermittent positive pressure ventilation (NIPPV) versus nasal continuous positive airway pressure (NCPAP) for preterm neonates after extubation. Cochrane Database Syst Rev 2014;9:CD003212.

2. Moretti C, Giannini L, Fassi C, Gizzi C, Papoff P, Colarizi P. Nasal flow-synchronized intermittent positive pressure ventilation to facilitate weaning in very low-birthweight infants: unmasked randomized controlled trial. Pediatr Int 2008;50(1):85-91.

3. Davis PG, Morley CJ, Owen LS. Non-invasive respiratory support of preterm neonates with respiratory distress: continuous positive airway pressure and nasal intermittent positive pressure ventilation. Semin Fetal Neonatal Med 2009;14(1):14-20.

4. Bhandari V, Finer NN, Ehrenkranz RA, Saha S, Das A, Walsh MC, et al. Synchronized nasal intermittent positive-pressure ventilation and neonatal outcomes. Pediatrics 2009;124(2):517-526.

5. Gao WW, Tan SZ, Chen YB, Zhang Y, Wang Y. Randomized trial of nasal synchronized intermittent mandatory ventilation compared with nasal continuous positive airway pressure in preterm infants with respiratory distress syndrome. Zhongguo Dang Dai Er Ke Za Zhi 2010;12(7):524-526. Article in Chinese.

6. Lemyre B, Davis PG, De Paoli AG. Nasal intermittent positive pressure ventilation (NIPPV) versus nasal continuous positive airway pressure (NCPAP) for apnea of prematurity. Cochrane Database Syst Rev 2002;1(1):CD002272.

7. Meneses J, Bhandari V, Alves J. Nasal intermittent positive-pressure ventilation vs nasal continuous positive airway pressure for preterm infants with respiratory distress syndrome. Arch Pediatr Adolesc Med 2012;166(4):372-376

8. Kirpalani H, Millar D, Lemyre B, Yoder BA, Chiu A, Roberts RS. A trial comparing noninvasive ventilation strategies in preterm infants. N Engl J Med 2013;369(7):611-620.

9. Bhandari V, Gavino RG, Nedrelow JH, Pallela P, Salvador A, Ehrenkranz RA, Brodsky NL. A randomized controlled trial of synchronized nasal intermittent positive pressure ventilation in RDS. J Perinatol 2007;27(11):697-703.

10. Goldsmith JP, Karotkin EH. Introduction to assisted ventilation. In: Goldsmith JP, Karotkin EH, editors. Assisted ventilation of the neonate, 3rd edition. Philadelphia: WB Saunders; 1996;1-19.

11. Johnston C, Melo DAS, Carvalho WB. Initial parameters for the application of NIPPV. In: De Carvalho WB, Johnston C, Barbosa $\mathrm{AP}$, editors. Noninvasive ventilation in neonatology and pediatrics, volume 1: pediatric and neonatal intensive care series. São Paulo: Editora Atheneu; 2007.

12. Lopes JMA. Neonatal apnea. J Pediatr 2001;77(Suppl 1):S97-S103.

13. Yong SC, Chen SJ, Boo NY. Incidence of nasal trauma associated with nasal prong versus nasal mask during continuous positive airway pressure treatment in very low birth weight infants: a randomized control study. Arch Dis Child Fetal Neonatal Ed 2005;90(6): F480-F483.

14. Rego MAC, Martinez FE. Clinical and laboratory repercussions of nasal CPAP in preterm newborns. J Pediatr 2000;76(5):339-348.

15. Courtney SE, Barrington KJ. Continuous positive airway pressure and noninvasive ventilation. Clin Perinatol 2007;34(1):73-92.

16. Bisceglia M, Belcastro A, Poerio V, Raimondi F, Mesuraca L, Crugliano C, Corapi UP. A comparison of nasal intermittent versus continuous positive pressure delivery for the treatment of moderate respiratory syndrome in preterm infants. Minerva Pediatr 2007;59(2): 91-95.

17. Owen LS, Morley CJ, Davis PG. Neonatal nasal intermittent positive pressure ventilation: what do we know in 2007? Arch Dis Child Fetal Neonatal Ed 2007;92(5):F414-F418.

18. Kugelman A, Feferkorn I, Riskin A, Chistyakov I, Kaufman B, Bader D. Nasal intermittent mandatory ventilation versus nasal continuous positive airway pressure for respiratory distress syndrome: a randomized, controlled, prospective study. J Pediatr 2007;150(5): 521-526.

19. Pantalitschka T, Sievers J, Urschitz MS, Herberts T, Reher C, Poets CF. Randomised crossover trial of four nasal respiratory support systems for apnoea of prematurity in very low birthweight infants. Arch Dis Child Fetal Neonatal Ed 2009;94(4):F245-F248. 